\title{
A Discrete Choice Experiment to Elicit the Willingness to Pay for Health Insurance by the Informal Sector Workers in Sierra Leone
}

\author{
Joseph Kamara ${ }^{1}$, Mireia Jofre Bonet ${ }^{2}$, Alice Mesnard ${ }^{2}$ \\ ${ }^{1}$ Sierra Leone Social Health Insurance (SLeSHI) Scheme, Freetown, Sierra Leone \\ ${ }^{2}$ Department of Economics, City University of London, London, UK \\ Email address: \\ joseph.kamara.1@city.ac.uk(J.Kamara)
}

\section{To cite this article:}

Joseph Kamara, Mireia Jofre Bonet, Alice Mesnard. A Discrete Choice Experiment to Elicit the Willingness to Pay for Health Insurance by the Informal Sector Workers in Sierra Leone. International Journal of Health Economics and Policy. Vol. 3, No. 1, 2018, pp. 1-12. doi: $10.11648 /$ j.hep.20180301.11

Received: March 17, 2018; Accepted: May 7, 2018; Published: May 29, 2018

\begin{abstract}
The current health care financing system in Sierra Leone is unsustainable and poses challenges ranging from increased in out of pocket health care expenditure to accessibility problems, particularly in rural areas where living standards are low and health care facilities are scarce. This paper investigates whether privately financed health Insurance can improve the accessibility to formal health care in Sierra Leone and mitigate the effects of OOPs on poor households. To do so, we estimate the Willingness To Pay (WTP) for health insurance among informal sector workers in Sierra Leone using a Discrete Choice Experiment approach. Eight informal sector activities were selected namely - petty trading, subsistence farming, commercial bike riding, cattle rearing, fishing, tailoring, mining and quarrying. A random effect logit model is used to estimate households' WTP for an improvement in coverage, choice of health care provider and a reduction in waiting time. Our study reveals that households were WTP more to have better attributes (better coverage, less waiting time) and to go to a faith - based provider. Our findings also suggest that location - rural versus urban - matters in determining the WTP since urban households were WTP more for health insurance than their rural counterparts, (SLL 54,348 or \$7.34) and (SLL 37,250.5 or \$5.03), respectively.
\end{abstract}

Keywords: Health Insurance, Willingness to Pay, Discrete Choice Experiment, Informal Sector, Sierra Leone, Sierra Leonean Leones

\section{Introduction}

Over 2 billion people living in developing countries are faced with health systems characterized by inefficiencies, poor quality services, inequitable access; inadequate funding; and high out of pocket (OOP) health care expenditures [10]. The high OOP payments for health care deter the poor, especially those in the informal sector, from accessing basic health care services.

Lack of access to health care and high health care expenditures are discussed in the literature as one of the primary causes of poverty and deprivation of rural households in poor countries. The poor often live without formal safety nets and suffer from high job insecurity, hence increasing their vulnerability to shocks that eventually leave them in severe poverty [19]. Improved health care financing mechanisms such as access to a low-cost health insurance scheme for low income households could help mitigate this situation. Health insurance schemes are central to improvements in the health status of a country's population, as they subsidize access to health services during periods of ill health [10]. Scholars argue that health insurance plays an important role in accessing medical care and reducing the high cost of OOP health care expenditures, improving health and the economic well being of people.

The question therefore is how much poor people are willing to pay for health insurance to avoid the uncertainty of the negative financial impacts associated to shocks of ill health. As health insurance is a non-marketed good, estimating the willingness to pay for health insurance will be essential. Willingness To Pay (WTP) is the most popular evaluation technique used to elicit preferences in health 
economics. WTP is a stated preference approach that estimates the maximum amount of money a person/household is willing to pay or give up to obtain a particular benefit or service being sold such as health insurance, health services or environmental products [21, 31]. WTP aims to determine how much individuals are prepared to pay to reduce their risk of mortality and morbidity from the present [28] or the demand society places on that product [16]. WTP can be estimated either through contingent valuation methods or through Discrete Choice Experiments (DCE), which are less prone to reporting biases in surveys [14].

The objective of this paper is to estimate WTP for health insurance among informal sector workers in Sierra Leone using a DCE approach. The key questions that this research tries to answer are, first, how much informal sector households are willing to pay for health insurance; second, whether location (rural or urban) matters in deciding WTP for health insurance and finally, which attributes the informal sector workers are most willing to trade.

The paper is structured as follows: First, is the description of the data set and the provision of some background information about DCE methods. Next, is to provide the econometric specification before presenting the results of the WTP estimates, which are compared between locations and different informal sector activities. Discussion of results and conclusion are presented in the last section.

\section{Background}

\subsection{Context}

The data for this study were obtained in Sierra Leone - a country of about 7 million people living along the west coast of Africa - by means of a DCE conducted in the northern and western regions of Sierra Leone. The choice of these specific regions was driven by one of the researcher's prior knowledge and familiarity, which enhances the quality of the data collected at least to a certain degree, as well as the accuracy of the econometric results [6].

This paper focuses on informal sector households, which have no contractual arrangement for health care, as opposed to formal sector employees. The informal sector workers coping with vulnerabilities like flooding, fire accident, sickness, famine etc. and the lack of a special scheme and considerations for this population makes their living conditions difficult [12]. Informal sector households facing poor health do not have formal safety nets to provide them with the necessary financial resources for basic consumption needs such as transportation, education and food and they do not access appropriate health care at the point of need because of lack of money [1].

The International Labour Office (ILO) in 1993 (during the fifteenth international conference of labour statisticians) defined informal sector as composed of entities engaged in the production of goods or services with the main objective of generating employment and income [32]. These entities operate at two levels of organizations - with little or no division between labour and capital, and on a small scale [32]. The labour regulations in these settings are based on casual employment, relatives, kinship, no contractual arrangements with formal guarantees etc.

The informal sector in Sierra Leone represents $45 \%$ of GDP, involving about two thirds of the working population and is dominated by different kinds of small - scale enterprises and business activities [40]. These activities include cookery, tailoring, carpentry, metal working, shoe making, baking, photography, watch and radio repairs, hair dressing, subsistence farming, commercial bike riding ("okada"), petty trading, cattle rearing, fishing, etc. [20]. Due to its wider scope and variety of activities, the informal sector absorbs a seemingly unlimited number of people in different occupations. Petty trading is the hallmark of the informal sector in Sierra Leone. The informal sector in Sierra Leone is characterized by poverty, low levels of education, economic and social deprivation and weak employment conditions. Therefore, for the purpose of this paper, a household whose main source of livelihood comes from petty trading, subsistence farming, commercial bike riding ("Okada"), cattle rearing, fishing, tailoring, alluvial mining, and quarrying is classified as an informal sector household.

\subsection{Data Collection}

Statistics Sierra Leone (SSL) designed the sample for this study based on recent pre-census data that has information on settlement names, population and household sizes. A twostage stratified random sampling method was used to identify the households. The first stage involved dividing the population into regions/districts, while in the second stage the population was divided into rural and urban areas in each district. The purpose was to ensure a representative sample of informal sector households in both villages (rural areas) and major towns (urban areas). Households were randomly chosen from both strata. The choice of the household as the economic unit stems from the notion that in poor informal households, the economic decision to purchase health care among these rural and mostly farming households is more likely to be a household rather than an individual decision.

The questionnaire developed is divided into three sections: (1) a question to help identify the informal sector the household is engaged in; (2) introduction to the DCE and the series of blocked choice questions to make a choice from; and (3) background questions on household socio-economic and demographic characteristics. A pilot study was done to test the attributes, their levels, the questionnaire and necessary corrections made before we undertake the final survey. The main survey was conducted within the period May to July 2013. Data entry staffs did the cleaning and entering of the data.

An interviewer administered the questionnaire and all households sampled $(1,670)$ agreed to participate in the study. The information was collected at the household level and thereby ensured that either the head of the household or his/her spouse answered the questions. In our final sample, 
we use the answers from a total of 1,458 households. We discarded 212 households responses (12.7\%): 66 of such households did not pass the dominance test, meaning they did not understand the DCE questions, and 146 households have incomplete data; hence their responses are excluded from the data. This was tested and based on their observable characteristics; the excluded households were not significantly different from the rest of the sample, which gives confidence that the results are unlikely to be biased by selection issues. Thus, the dataset contains the answers of 1,458 households, which were given 9 choice sets with 2 alternatives each, i.e. having a total of 26,244 observations.
Definitions and descriptive statistics of the health care package and the attributes chosen, the socio-economic and demographic characteristics of the households in the sample used are reported in Table 1 below. For each variable, the means in rural and urban areas, the mean difference across locations, standard errors and statistical significance of the difference were shown. Overall, the results show that the distribution of the health insurance scheme attributes and household characteristics varies significantly between households that live in rural versus urban areas in terms of income, occupation and levels of education.

Table 1. Variable definitions.

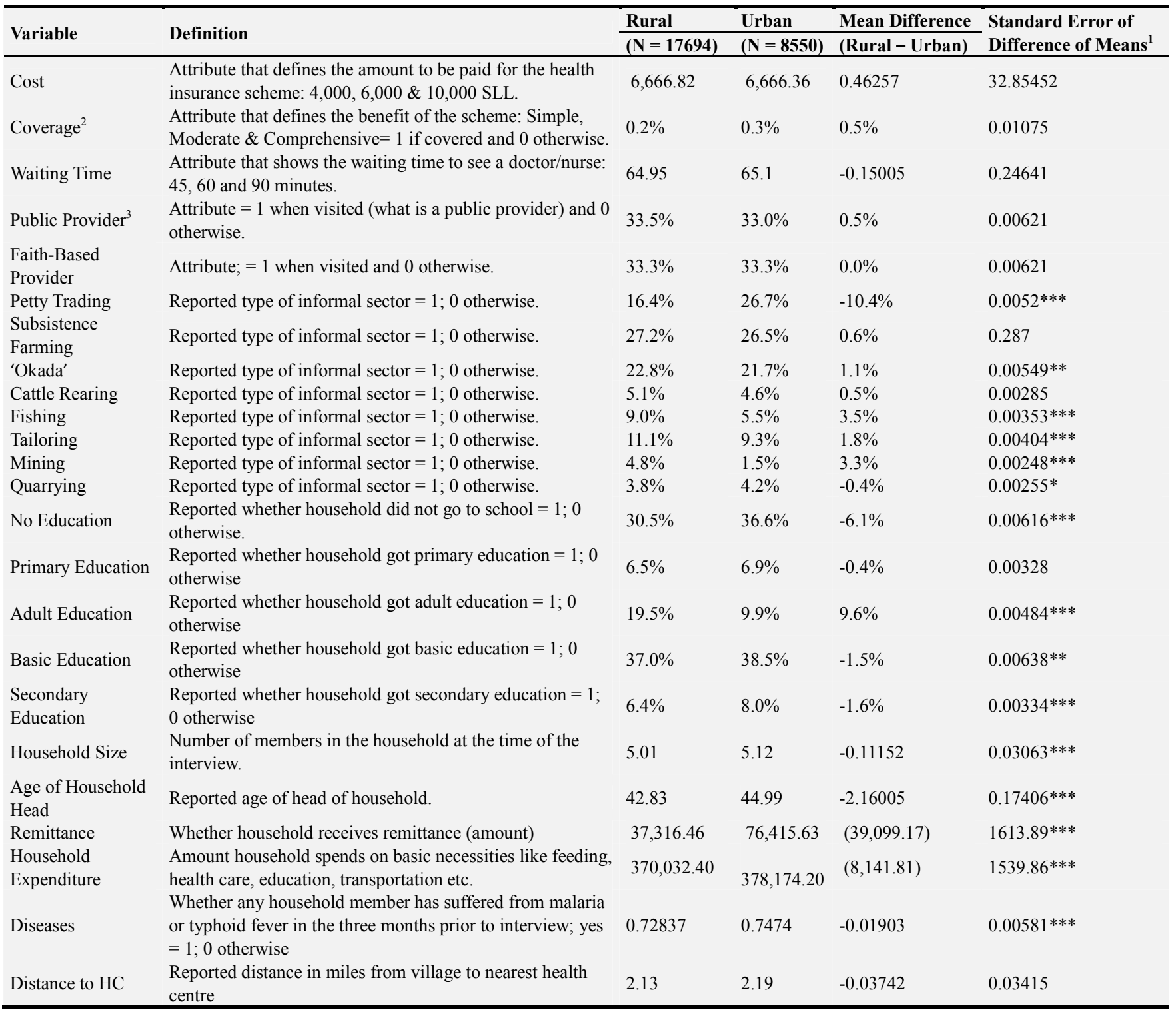

Notes:

1. Significant differences are indicated by $* * *$ if $\mathrm{p}<0.01$, $* *$ if $\mathrm{p}<0.05$ or $*$ if $\mathrm{p}<0.1$.

2. Simple coverage covers Primary Health Care Diseases and Minor Operations; Moderate coverage refers to coverage of Secondary Health Care Diseases including major operations; and Comprehensive coverage covers Tertiary Health Care Diseases. However, this work uses Moderate Coverage as the definition of Coverage throughout this paper.

3. Provider here refers to owners of health facilities including hospitals, clinics, diagnostic centres etc. 


\subsection{Discrete Choice Experiment Design}

There has been a growing interest and increasing number of studies using DCE methodology in Environmental and Health Economics studies since it's introduction in the 1980s $[5,11,16$, $29,30,38]$. In this study, a DCE methodology was used to investigate households' WTP for health insurance [39]. ${ }^{1}$ Within the stated preference methods used in the literature, the increasing success of choice modeling rests on its ability to simultaneously allow for the estimation of the relative importance or trade-offs between the health insurance attributes, and the total benefit households derive from such service. DCEs are based on the idea that households derive utility not from a good per se but from the underlying attributes of the good [22]. In this context, DCEs present households with alternative descriptions of a health insurance scheme differentiated by combinations of attribute levels. Households are asked to choose their preferred alternative. One of the main assumptions inherent in a DCE is, for each choice made, the chosen alternative is assumed to yield a higher level of satisfaction than the one rejected. This allows the probability of the chosen alternative to be modeled in terms of attribute levels.

This study follows the five stages highlighted in undertaking a DCE [33]. This raises few issues mainly to determine the overall policy objective and the type of choice experiment to be designed [18, 23, 34], which we consider in the next subsections.

\subsubsection{Choosing Attributes and Levels}

During the survey, the households were asked to make a choice between two health insurance schemes, A and B. First, the study started by identifying the attributes relevant to describe the two health insurance schemes and to be used in the DCE design. For this purpose, a search through the literature was done and thereby identified 10 attributes. $^{2}$ A list with the 10 attributes was sent to 50 households and each household was asked to rank the 10 attributes in order of importance. The main question in this pre-test survey read: "Assuming a national health insurance scheme is to be introduced in the country, what are the key factors you will take into consideration before joining the said scheme, and from the list of attributes shown, please tick according to your order of preference".

The four most important attributes the households chose were coverage, waiting time, choice of health care provider and cost. Coverage as an attribute refers to the type of benefit the scheme will provide to members. Waiting time refers to the time it will take for a member to see a medical worker upon their visit to a hospital or a health centre. The choice of health care provider refers to the type of health care insured people will be able to access namely: Public, faith-based and private providers. Cost refers to the amount of money or premium to pay in order to participate in the health insurance

1 To the best of our knowledge, this is the only published paper that used DCE to estimate WTP for health insurance

2 The attributes include cost, coverage, choice of provider, waiting time, information, choice of drugs, new method of treatment, frequency in use of benefits, location of providers, and terminal diseases to be fully covered. scheme chosen. Cost is one essential attribute in all WTP for health insurance studies as it allows to monetarise the value respondent's place on the rest of the attributes (see more details with the econometric model). These four chosen attributes are widely used in the literature in estimating WTP and are plausible, quantifiable and above all easily recognized by the respondents.

In line with the preceding argument and WTP studies in developing countries, three levels were assigned to each of the attributes chosen. The final four attributes and their three levels each are shown in Table 2 below.

Table 2. Attribute and Levels used in the study.

\begin{tabular}{|c|c|c|}
\hline Attributes & Attribute Levels & Description \\
\hline Coverage & $\begin{array}{l}\text { Simple } \\
\text { Moderate } \\
\text { Comprehensive }\end{array}$ & $\begin{array}{l}\text { Primary Health Care Diseases } \\
\text { and Minor Operations } \\
\text { Secondary Health Care Diseases } \\
\text { and Major Operations } \\
\text { Tertiary Health Care Diseases }\end{array}$ \\
\hline Waiting Time & $\begin{array}{l}45 \text { Minutes } \\
60 \text { Minutes } \\
90 \text { Minutes }\end{array}$ & $\begin{array}{l}\text { The length of time one has to } \\
\text { wait before seeing a medical } \\
\text { personnel }\end{array}$ \\
\hline $\begin{array}{l}\text { Choice of } \\
\text { Provider }\end{array}$ & $\begin{array}{l}\text { Private } \\
\text { Public } \\
\text { Faith-Based }\end{array}$ & $\begin{array}{l}\text { Health centres and hospitals owned } \\
\text { and operated by private people } \\
\text { Health centres and hospitals owned } \\
\text { and operated by Government } \\
\text { Health centres and hospitals owned } \\
\text { and operated by faith-based } \\
\text { organisations }\end{array}$ \\
\hline Cost/Premium & $\begin{array}{l}\text { 4000SLL }(0.54 \mathrm{USD}) \\
6000 \mathrm{SLL}(0.81 \mathrm{USD}) \\
10000 \mathrm{SLL}(1.35 \mathrm{USD})^{3}\end{array}$ & $\begin{array}{l}\text { The monthly premium a member } \\
\text { will pay for the scheme }\end{array}$ \\
\hline
\end{tabular}

The three choices of providers were selected based on what exists in Sierra Leone. There are three types of health care facilities in Sierra Leone namely; private, public (government owned) and faith-based providers. The private facility is owned and operated by private individuals or families. The public or government facility is owned and managed by government. The faith-based facilities are owned and operated by religious organizations and/or non-governmental organizations. However, the payment of salaries depends on the type of arrangement with government. The government pays the salaries of some of the faith-based facilities staff, whereas for the others, their salaries are funded by the faithbased organizations themselves.

\subsubsection{Experiment Design}

The first process involved the identification of the attributes and assigning levels to them. Then, choice profiles are generated from combining attributes and levels. To ensure the cognitive burden of respondents is reduced to a workable size, a fractional factorial design (FFD) ${ }^{4}$ is used to reduce the number of profiles to a manageable number without losing

3 The exchange rate used right through this work is at November 2016; $\$ 1=$ 7400 SLL.

4 A fractional factorial design involves the selection of a portion of all possible profiles, in which the properties of the full factorial design are maintained such that the effects of interest can be calculated as efficiently as possible. 
the chance of estimating main effects in the design. A total of 18 choice profiles were generated using the FFD, subsequently structured into two blocks of 9 choice sets each. An extra tenth choice question is included in each block to test whether households understand the DCE questions. Hence, each household was presented with 10 choice questions -9 for the main DCE and 1 to test the level of understanding of the questions. Table 3 below gives an example of a choice set as shown in the questionnaire.

Table 3. Example of a choice set used in the questionnaire.

\begin{tabular}{lll}
\hline & $\begin{array}{l}\text { Health Insurance } \\
\text { Scheme A }\end{array}$ & $\begin{array}{l}\text { Health Insurance } \\
\text { Scheme B }\end{array}$ \\
\hline Coverage $^{5}$ & Comprehensive & Simple \\
Waiting Time (Minutes) & 45 & 90 \\
Choice of Provider & Public & Contracted \\
Cost (SLL) & 4,000 & 6,000 \\
Which Scheme would you prefer & & \\
\hline
\end{tabular}

All the attribute levels are presented and described to respondents before carrying out the choice experiments. The essence of this process is to minimise the size of 'warm glow' biases, which can affect stated preference methods [3]. In addition to the choice questions, the questionnaire captured relevant socio-economic characteristics for each household.

Based on the aforementioned, the efficiency of the experimental design compared to the full design is assessed at $91.7 \%$, using [37] website. ${ }^{6}$

\section{Empirical Strategy}

The theoretical basis for the model estimation is based on the Random Utility Theory (RUT), which explains that the choice of a health insurance scheme is made based on the scheme with the highest utility [26]. One assumption made is that the utility of a household is a linear and additive function of attributes wherein a change in the level of one attribute does not affect the marginal utility of another attribute. Thus, following $[4,15,27,36]$ we estimate the model thus:

$$
\begin{gathered}
U_{i j}=\beta_{0}+\beta_{1} \operatorname{Cov}_{i j}+\beta_{2} \operatorname{Cost}_{i j}+\beta_{3} \text { Pubchh }_{i j}+ \\
\beta_{4} \text { Contch }_{i j}+\beta_{5} \text { Wait }_{i j}+\alpha_{i}+\varepsilon_{i j}
\end{gathered}
$$

where the subscripts $i$ and $j$ refer to household $i$ and household's choice of health insurance scheme $j$, respectively; $\operatorname{Cov}_{i j}$ refers to coverage of the health insurance scheme $j$ chosen by household $i$; $P u b c h h_{i j}$ means the chosen scheme $j$ is provided by a public supplier; Contch $_{i j}$ that the provider is faith-based; and $W_{a i t}{ }_{i j}$, the waiting time associated to the choice $j . \alpha_{i}$ the household fixed effect and $\varepsilon_{i j}$ the household's choice idiosyncratic error, which we assume are not correlated, i.e. $\operatorname{corr}\left(\alpha_{i}+\varepsilon_{i j}\right)=\rho[13,25]$.

The coefficient $\beta_{0}$, the intercept, captures the overall performance of the health insurance $j$ when all other attributes are set at the default categories [35]. ${ }^{7}$ The rest of

\footnotetext{
5 Moderate coverage is used as the definition of coverage right throughout this work

$6 \mathrm{http}: / /$ crsu.science.uts.edu.ac/choice.

7 Scott (2001) explained that the constant term is included in a DCE model to test
}

the coefficients, $\beta_{1}$, to $\beta_{5}$, are interpreted as the marginal utilities of each of the five attributes of health insurance.

The sign and the statistical significance of each coefficient is used to quantify the relative importance of the attributes. This allows calculating the Marginal Rate of Substitution (MRS), i.e. how respondents are willing to trade an improvement in one attribute in order to forgo the other attribute. Because one of the health insurance scheme $j$ attributes is cost, we can calculate the WTP for attribute $k$ by using the MRS between cost and attribute $k$, i.e. using the ratio of the marginal utility of attribute $k$ over that of cost [34]:

$$
W T P_{j k}=-\frac{\partial V / \text { attribute } j k}{\partial V / \text { cost }_{j}}=-\frac{\beta_{j k}}{\beta_{\text {cost }}}
$$

To estimate equation (1), we apply a binary choice model [37] using the random effects logit model in STATA/SE 13.1.

\section{Results}

\subsection{Empirical Results}

The first part of the analysis looks at the regression results for the entire sample and sub-samples - by type of location and informal sector activity. ${ }^{8}$ Second, estimating household's overall WTP using the sub-samples. The third part of the analysis looks at welfare changes and the theoretical validity of the model.

Table 4 below summarizes the results of the logit model used to analyze the impact of each attribute on the choice of a health insurance scheme. In terms of goodness of fit, for the overall sample, the attributes are statistically significant at the $95 \%$ confidence level. The statistical significance of each attribute is tested using the Wald test. Results show that all chosen attributes are statistically significant $(\leq 0.05)$, recognizing that the type of coverage, cost of the health insurance scheme, type of provider (public/private, faith-based or not), and waiting time all significantly influence a household's choice of health insurance scheme. The negative coefficients associated to cost and waiting time are in line with theory; the higher the cost of a health insurance scheme, the less likely people are WTP for it. And, the higher the waiting time, the less likely people are WTP for the scheme. The positive coverage coefficients indicate that households are WTP more for an improvement in coverage. Moreover private providers are not financially accessible to most of the households, which is an important determinant of their choice as shown in Table 4, both by the positive coefficient associated to Public type of provider and the negative effect of costs. Households in the informal sector are also WTP more for faith-based providers. These results are in line with expectations and therefore provide support for our model.

and control for model misspecifications that arise, from either unobserved dimensions or unobserved interactions between household's socioeconomic/demographic characteristics and dimensions.

8 We estimate WTP for each informal sector in order to know which ones are WTP more than the others and to guide policy makers. This information is useful for planning cooperative insurance schemes, which are based on occupations and are becoming common in SSA. 
Table 4. Regression results: main sample and by location.

\begin{tabular}{|c|c|c|c|c|c|c|}
\hline \multirow{2}{*}{ Choice } & \multicolumn{2}{|c|}{ Main Sample } & \multicolumn{2}{|c|}{ Rural Household } & \multicolumn{2}{|c|}{ Urban Household } \\
\hline & Coefficient & Standard Error & Coefficient & Standard Error & Coefficient & Standard Error \\
\hline Coverage $^{* 9}$ & 0.54596 & $0.01624 * * *$ & 0.52670 & $0.02218 * * *$ & 0.57192 & $0.02393 * * *$ \\
\hline Waiting Time & -0.00793 & $0.00071 * * *$ & -0.00664 & $0.00096 * * *$ & -0.00952 & $0.00104 * * *$ \\
\hline Public Provider & 0.05376 & $0.01590 * * *$ & 0.03083 & 0.02179 & 0.08071 & $0.02329 * * *$ \\
\hline Faith-Based Provider & 0.5650 & $0.01641 * * *$ & 0.44470 & $0.02225 * * *$ & 0.70485 & $0.02446 * * *$ \\
\hline Cost & -0.00009 & $5.33 \mathrm{e} 06^{* * *}$ & -0.00009 & $7.28 \mathrm{e} 06 * * *$ & -0.00008 & $7.84 \mathrm{e}-06^{* * *}$ \\
\hline Constant & 0.75884 & $0.06273 * * *$ & 0.68839 & $0.08521 * * *$ & 0.850002 & $0.093005 * * *$ \\
\hline No of Obs. & 26244 & & 13770 & & 12474 & \\
\hline Wald chi2 (5) & 2553.25 & & 1121.51 & & 1472.88 & \\
\hline Prob $>$ chi2 2 & 0.0000 & & 0.0000 & & 0.0000 & \\
\hline Log Likelihood & -16713.37 & & -8912.80 & & -7762.7474 & \\
\hline
\end{tabular}

*** Indicates significant at $\mathrm{p}<0.01 ; *$ Coverage here refers to Moderate Coverage.

According to Table 4, results for both types of locations are very similar except that the effect of public provider on the provider choice is not significant for rural households. Moreover, the coefficients associated to most of the attributes apart from costs are slightly higher in magnitude for urban households than rural ones, which could be due to their level of awareness/understanding. The number of households that listen to a radio or read a newspaper captures this in the survey. ${ }^{10}$

Table 5 below presents the econometric results by type of activity in the informal sector. From this Table, we observe that all attributes have significant coefficients across activities except for: petty trading (wherein public provider is not significant); and mining and quarrying (wherein waiting time and public provider are not significant).

Table 5. Regression result for informal sector economic activities.

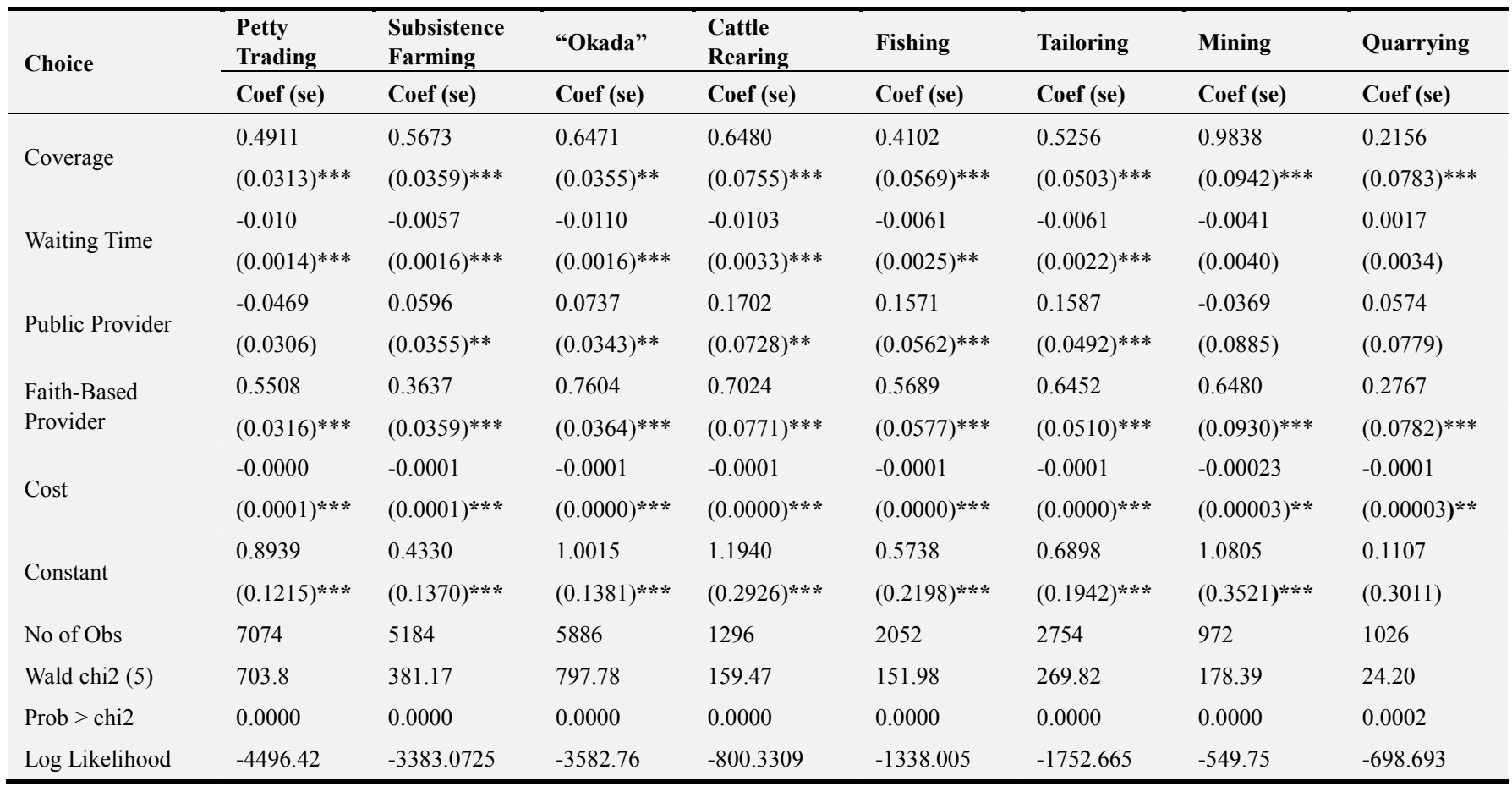

$* * * \mathrm{p}<0.01 ; * * \mathrm{p}<0.005 ; * \mathrm{p}<0.1$

9 When we use any two kinds of coverage (simple and moderate; simple and comprehensive; and moderate and comprehensive) at any point in our regression, the results obtained move in the opposite direction of theory. For instance, we expect cost to be negative and coverage (of any kind) to be positive, but the result gives the opposite. Therefore, one type of coverage (moderate) was used right through and our results hinges on this.

10 In the survey, we asked households whether they listen to the news or read newspapers. If the person answers yes, then it means they are often aware of currents issues and development in the country. 


\subsection{Willingness to Pay}

As described above, the DCE method allows one to estimate WTP when cost or price or out of pocket expenses is one of the attributes used in the experiment [5]. This involves calculating the MRS, which is the rate at which a household is willing to substitute (i.e., give up) one attribute in order to get one unit of the other attribute according to the estimated coefficients. It is the absolute value of the ratio of the coefficients associated to any two attributes used in the study (see equation 2). The direction and the interpretation depend on what the denominator is.

We estimate WTP by replacing the denominator of the MRS with the cost coefficient. The WTP for health insurance is the amount of money a household is willing to forgo each month in order to attain an improvement in their health status. It is the monetary value households place on each health insurance attribute. Table 6 presents household WTP results for the main sample and type of location (see Appendix for individual WTP estimates).

Table 6. Household WTP estimates ${ }^{11}$.

\begin{tabular}{|c|c|c|c|c|c|c|}
\hline \multirow{2}{*}{ Attributes } & \multicolumn{2}{|l|}{ Full Sample } & \multicolumn{2}{|c|}{ Rural Location } & \multicolumn{2}{|c|}{ Urban Location } \\
\hline & WTP (SLL) & $\%$ of Income & WTP (SLL) & $\%$ of Income & WTP (SLL) & $\%$ of Income \\
\hline Total WTP ${ }^{1}$ & $44,428.5$ & 13.3 & $37,250.5$ & 8.5 & 54,348 & 16.4 \\
\hline Coverage & 31,965 & 9.6 & 28,500 & 8.6 & 36,568 & 10.8 \\
\hline Public Provider & 3,148 & 0.9 & 1,668 & 0.5 & 5,160 & 1.5 \\
\hline Faith-Based Provider & 33,080 & 9.9 & 24,063 & 7.3 & 45,067 & 13.3 \\
\hline Waiting Time ${ }^{2}$ & 464 & 0.1 & 360 & 0.1 & 609 & 0.2 \\
\hline
\end{tabular}

Notes: WTP figures are expressed in Sierra Leone's local currency - Leones.

1. The total/overall WTP includes the amount the household is willing to pay for the health insurance scheme.

2. Given the negative effect of waiting time, these estimates represent what individuals would need to be compensated for an increase in waiting time by one minute.

Overall, households' WTP is $44,428.5 \mathrm{SLL} / \$ 6$ per month (about $13.3 \%$ of their income) for health insurance which is in line with similar studies: first, Burkina Faso with an individual WTP of $\$ 3.17$ and $\$ 4.25$ using the take it or leave it (TIOLI) and bidding games respectively [9]; another work on WTP for health insurance was in Namibia wherein they found out that over $50 \%$ of uninsured respondents are WTP $\$ 6.60$ per month [2]; one other study in Rural Cameroon estimated that rural households are WTP $\$ 2.15$ per person/month for health insurance [8]; (Note that all these studies used contingent valuation method in contrast to the DCE method used here). On average, households are WTP 31,965SLL/ $\$ 4.32$ (about 9.6\% of average household income) for an improvement in coverage, 33,080SLL $\$ 4.47$ (about $9.9 \%$ of household income) for having a faithbased health care provider, and 3,148SLL/ $\$ 0.43$ (about $1 \%$ of household income) to have a public health care provider and are WTP $464 \mathrm{SLL} / \$ 0.06$ (about $0.1 \%$ of their income) for a minute reduction in waiting time (equivalent to a WTP of $27,840 \mathrm{SLL}$ for a 60 minutes reduction in waiting time, or about $3.8 \%$ of household's income). ${ }^{12}$ There are vast differences in households WTP across locations. Urban households are WTP about $28 \%$ more than rural households for an improvement in coverage; they are also WTP about 2 and 3 times more to have a faith-based or public provider respectively. Urban households are also WTP about $249 \mathrm{SLL} / \$ 0.03$ more than their rural counterparts for a minute reduction in waiting time. However, comparing rural to urban households, overall, the latter is willing to pay 20,097.5SLL/ $\$ 2.72$ (about $5.9 \%$ of urban household income) more than what their rural counterparts are WTP. For a 60 minute reduction in waiting time, Urban households are WTP about 14,940 SLL (about $4.4 \%$ of household's income) more than their rural counterparts.

To also estimate the WTP for households based on income levels, four income levels were generated as shown below:
Income Level One:
75,000 SLL
218,751 SLL
218,750 SLL
Income Level Two:
$362,501 \mathrm{SLL}$
362,500 SLL
Income Level Three:
$506,251 \mathrm{SLL}$
506,250 SLL
650,000 SLL

A random effect logit model is use to estimate the impact of each attribute on the choice of a health insurance scheme for households by level of income (See appendix for regression results). From these results, WTP for each attribute according to the income levels is estimated and the results shown in table 7 below.

11 We assume a household has 5 members, as it is the average household size in our survey.

12 An exchange rate of 7400SLL to \$1USD was used. 
Table 7. WTP by income levels.

\begin{tabular}{|c|c|c|c|c|c|c|c|c|}
\hline \multirow[b]{2}{*}{ Attributes } & \multicolumn{2}{|c|}{ Income Level 1} & \multicolumn{2}{|c|}{ Income Level 2} & \multicolumn{2}{|c|}{ Income Level 3} & \multicolumn{2}{|c|}{ Income Level 4} \\
\hline & $\begin{array}{l}\text { WTP } \\
\text { (SLL) } \\
\end{array}$ & $\begin{array}{l}\text { Percent of } \\
\text { Income }\end{array}$ & $\begin{array}{l}\text { WTP } \\
\text { (SLL) } \\
\end{array}$ & $\begin{array}{l}\text { Percent of } \\
\text { Income }\end{array}$ & $\begin{array}{l}\text { WTP } \\
\text { (SLL) } \\
\end{array}$ & $\begin{array}{l}\text { Percent of } \\
\text { Income }\end{array}$ & $\begin{array}{l}\text { WTP } \\
\text { (SLL) } \\
\end{array}$ & $\begin{array}{l}\text { Percent of } \\
\text { Income }\end{array}$ \\
\hline Coverage & $5,777.3$ & 3.4 & $6,790.7$ & 2.3 & $6,603.8$ & 1.6 & $7,124.6$ & 1.3 \\
\hline Waiting Time $^{1}$ & 87.3 & 0.1 & 96.7 & 0.0 & 104.3 & 0.0 & 17.3 & 0.0 \\
\hline Faith-Based Provider & $10,426.4$ & 6.1 & $15,808.8$ & 5.3 & $12,956.1$ & 3.1 & 12,713 & 2.3 \\
\hline Public Provider & 970.8 & 0.6 & $2,500.2$ & 0.8 & $3,066.4$ & 0.7 & $2,857.1$ & 0.5 \\
\hline Total WTP & $15,320.1^{2}$ & 8.9 & $25,196.3$ & 8.4 & 22,731 & 5.50 & 24,712 & 4.44 \\
\hline No of Observation & 3924 & & 11736 & & 9054 & & 2412 & \\
\hline
\end{tabular}

Notes: SLL refers to Sierra Leonean Leones (local currency in Sierra Leone)

1. Given the negative effect of waiting time, this estimate represents what individuals would need to be compensated for an increase in waiting time by one minute.

2. Given the negative effect, this estimate represents what households of income Level 1 are WTP for not having (forgo) a public provider.

Table 7 shows that households on the lowest income are WTP about 15,320.1SL (or about 9\% of household income) for an improvement in coverage (from moderate to comprehensive), a reduction in waiting time by one minute, having a faith-based provider (rather than a private or public provider). This is substantially lower than for households with the highest income level who have a WTP of about 24,712 SLL. However, households on the lowest income level, WTP represent a higher proportion of their income $(8.9 \%)$. However, as income increases, the WTP for health insurance represents a lower percent of household's income $(5.5 \%$ and $4.4 \%$ for income levels three and four respectively).

\subsection{Welfare Changes}

One of the primary reasons for using a DCE to elicit WTP for health insurance is to be able to estimate welfare changes associated to changes in health care policies. One can do so by using the concept of compensating variation $(\mathrm{CV})$, in the case of switching health insurance schemes the CV is the monetary equivalent associated to the loss of utility due to the switch.

As an illustration, consider two hypothetical health insurance scenarios (best and worst) and calculate the CV of switching from one to another. The first scheme (worst case) provides moderate coverage wherein households can go to a public provider, with a waiting time of 90 minutes and a cost of 10,000SLL per household member. The second scheme (best case) provides moderate coverage by a faith-based provider, a waiting time of 45 minutes, at a cost of 4,000SLL per household member. Following Small and Rosen (1981) in [34], the change in welfare associated to the switch from a public provider scheme to a faithbased provider is the $\mathrm{CV}$, i.e. $\mathrm{CV}=$ $\frac{1}{-\beta_{\text {cost }}}\left[\ln \left(\sum e^{V \text { contchh }}\right)-\ln \left(\sum e^{V \text { pubchh }}\right)\right] \quad, \quad$ where $\ln$ $\left(e^{V \text { Vontchh }}\right)$ is the indirect utility associated to the faithbased provider and $\ln \left(e^{V p u b c h h}\right)$ is the indirect utility associated to having a public health care provider. Table 8 below shows the $\mathrm{CV}$ for the full sample and for the different subsamples.
Table 8. Probabilities and compensating variation (CV) for hypothetical $\operatorname{case}^{13}$.

\begin{tabular}{lllll}
\hline \multirow{2}{*}{ Sample } & \multicolumn{3}{l}{ Probabilities $^{\mathbf{1}}$} & \multicolumn{2}{l}{ Compensating Variation } \\
\cline { 2 - 5 } & Pubchh & Contchh & CV (SLL) & CV (USD) \\
\hline Full Sample & 0.37490 & 0.62510 & $10,180.42$ & $\$ 1.38$ \\
Rural & 0.39799 & 0.60201 & $9,235.18$ & $\$ 1.25$ \\
Urban & 0.34884 & 0.65116 & $11,477.51$ & $\$ 1.55$ \\
Petty Trading & 0.35487 & 0.64513 & $11,496.51$ & $\$ 1.55$ \\
Subsistence Farming & 0.42457 & 0.57543 & $9,491.67$ & $\$ 1.28$ \\
Okada & 0.33477 & 0.66523 & $11,223.38$ & $\$ 1.52$ \\
Cattle Rearing & 0.37001 & 0.62999 & $9,557.42$ & $\$ 1.29$ \\
Fishing & 0.39849 & 0.60151 & $11,296.43$ & $\$ 1.53$ \\
Tailoring & 0.38072 & 0.61928 & $9,377.16$ & $\$ 1.27$ \\
Mining & 0.33517 & 0.66484 & $6,786.02$ & $\$ 0.92$ \\
Quarrying & 0.44538 & 0.55462 & $4,408.03$ & $\$ 0.60$ \\
\hline
\end{tabular}

Notes:

1. The probability of choosing a certain type of provider $k$ is calculated as $P_{i k}=\frac{e^{V_{i k}}}{\sum_{j=1}^{J} e^{V_{i j}}}$, where $J=3$ is the number of different types of providers available.

2. Assuming exchange rate of 7400 SLL to $\$ 1$.

Based on the estimated utilities, a household prefers the faith-based provider than the public one as, ceteris paribus; the probability of choosing the former is almost twice that of the latter. When comparing the various informal sectors, the argument is similar: The probability for faith-based provider is higher for "Okada" riders, petty trading and mining sectors. These are sectors predominantly urban, especially the first two. However, the probability of choosing the public provider is higher for households in informal sectors predominantly in rural settings or just outside urban areas, (quarrying, subsistence farming, tailoring and fishing).

The CV does calculate the extent to which individuals are willing to trade money for the change in the type of provider. The CV associated to changing from the public provider health insurance scheme to the faith-based provider, which implies a decrease in the cost of health insurance of 30,000 SLL (40,000SLL-10, 000SLL) and a reduction in the waiting time of $45 \mathrm{~min}(90 \mathrm{~min}-45 \mathrm{~min})$ is $10,180.42 \mathrm{SLL}$ or $\$ 1.38$. According to our calculation, households in urban locations have a higher $\mathrm{CV}$, implying, they are willing to pay a higher

13 These estimates are for individual members. The average number of members in a household is five. 
amount than their rural counterparts (about 25\%) to switch to the faith-based provider, which supports earlier WTP results. A possible explanation is the higher level of awareness amongst these urban households. Among the informal sectors, households in petty trading, "okada" and fishing have higher CV's because they live in urban areas or semi - urban dwellings.

\subsection{Tests of Validity of Responses}

The validity of responses basically ensures that the entire measurement process i.e. the collection of data and its analysis must not only be reliable but also free of systematic and uncontrolled bias that distort the estimated results. Two approaches are used in this study to test for internal validity.

The first approach, consistency of preferences, is tested by including another pair of choice set in the DCE making the pair of choice sets to be 10 . The $10^{\text {th }}$ choice set include levels of attributes such that one alternative had better levels on all attributes. If households understand the DCE questions, we would expect them to choose the scheme with better levels of attributes. Only 66 households (4\% of the sample) did not pass the test of consistency of preferences, in which case they were dropped from the sample.

The second test is the theoretical validity wherein the sign and significance of parameter estimates are examined. To perform this test, interaction terms were created between the attribute cost and a characteristic of the household income. We do the same with the attribute waiting time. As per equation 2 , we recalculated the WTP by inserting in the numerator the waiting time for a given level of income and in the denominator the coefficient of cost for that given level of income. We hypothesized that as income increases; households are WTP more for a reduction in waiting time [30].

Wald tests are used to test whether the newly constructed interaction variables are statistically different from each other. The $\mathrm{z}$ test is also used to test for significant differences in the resulting WTP values at different income level obtained by computing the ratio between the marginal effects of waiting time (numerator) and the marginal effects of costs at each level of income. A priori, it is expected that as income increases, households are WTP more for a reduction in waiting time. The results (available upon request) confirm that the interaction variables are statistically different from each other and that income levels are positively and significantly associated with the WTP values for a reduction in waiting time, which lends credence to our validity test.

\section{Discussion and Conclusion}

This paper studies household's WTP for health insurance among informal sector workers using the DCE. Eight informal sectors are chosen including petty trading, subsistence farming, commercial bike riding (Okada), cattle rearing, fishing, tailoring, quarrying, and mining. To the knowledge of the authors, this is the first study that estimates WTP for health insurance among informal sector workers in a Sub-Saharan African country context using the DCE methodology. It also looks at the issue of theoretical validity and shows that households living in urban areas have higher WTP than rural households.

The benefits of using DCEs have been highlighted in the literature ranging from its capacity to estimate WTP, the preference for attributes in a given choice set and measuring welfare effects of a policy change [24, 33, 34]. Despite these advantages, the application of DCEs to estimate WTP especially in developing countries remains low. One possible suggestion is that developing countries are plagued with different cultural and language settings and high illiteracy rates, which renders the use of DCEs challenging [24].

The WTP estimated for Sierra Leone is in line with other studies within developing countries, that is, on average, an individual is willing to pay about $\$ 3$ for health insurance. ${ }^{14}$ In contrast to these, this study used the DCE method and disaggregated the results by location and across the eight main informal sector activities in Sierra Leone. The results show that the faith - based provider and coverage are the most important attributes in determining a households' choice of health insurance scheme. Waiting time to see a medical staff and accessing a public provider are considered the least important attributes in determining a households' choice of health insurance scheme.

Moreover, this study shows a pattern: coverage is the most important attribute for households in activities predominant in rural settings whereas faith-based provider is predominantly significant for urban or near urban settings. The result also shows that the probability of a household choosing a faith - based provider is almost twice the probability of choosing a public provider. This suggests that the public health care system in this setting, like perhaps in other African countries, is in an appalling situation (possibly highly corrupt). Hence households prefer the faith-based system. To increase people's well-being policy makers may want to invest more into faith - based providers, as about $60 \%$ of households prefer such schemes.

The results also show that it does make a difference whether you are located in the rural area or urban area [in line with 39]. Urban households are WTP about 54348 SLL/ $\$ 7.34$ (about $16.4 \%$ of urban household's income) more than rural households for health insurance. Possible explanation for this higher WTP for health insurance by urban households is that they have a better income, better level of education and higher level of awareness, which in line with the literature; higher income, education and awareness increase ones WTP.

In terms of WTP for improvements in any of the attributes, urban households are WTP about 50\% more than their rural counterparts for an improvement in coverage. This difference is due to the level of awareness and understanding with regard to health issues, which are higher among urban households than their rural counterparts, hence they are able

14These studies used the contingent valuation method as opposed to the DCE method this paper uses. 
to know which coverage will make them better off. Moreover, urban households compared to rural households are WTP about 2 times more for having a faith - based provider and about 28 percent more for having an improvement in coverage. In terms of waiting time, households in rural and urban areas are quite similar.

In line with theory, it was also found out that household's income matters; households on higher income are willing to pay more but cover a proportionately smaller fraction of their income, whereas, those on lower income are willing to pay less and covers a proportionately higher percentage of their income.

The study also shows that the probability of a household choosing a faith-based type of provider is about twice that of choosing a public type of provider. Households are willing to pay about 10,180 SLL $/ \$ 1.38$ for switching to a faith-based provider, a decrease in cost from 10,000 SLL to 4,000 SLL and a reduction in waiting time from 90 minutes to 45 minutes.

The paper also tested for the validity of responses and the result lends credence to the study. External validity could not be tested on the grounds that it is still difficult to estimate. However, some studies do assume sufficient external validity for their study [38].

This study has some methodological limitations. The first, which is a weakness of the DCE method, is that respondents sometimes experience difficulties when answering the questions. In particular, interviewers find it difficult to recall issues regarding health care expenditure mentioned by respondents or difficulties in understanding the DCE process, hence spending longer than normal times. In addition, disadvantages of face-to-face interviews are that it takes respondent's time to complete, which is costly, and interviewer bias may have arisen due to this fact. Secondly, the experimental design limits the number of levels for each attribute. The equal levels of attributes in the DCE design used in this study (i.e. three levels for each attribute), may impose a cost on the experiment because some attributes may naturally require more than three levels [17 pp. 108]. More levels of attributes would have involved higher expenses and more difficulties for respondents to understand the experiment. A third limitation is related to sampling and nonsampling errors. However, increasing the sample size and the method used to select the sample mitigated the issue of sampling error. The sample used was estimated ensuring that it meets the minimum sample size requirement for a DCE (see [7] for a detailed analysis of estimating sample size). However, non-sampling error remains the most important source of error in the estimates and may arise from many different sources. Interviewers may make mistakes in the collection of data or respondents may also forget activities such as hospital visits or the associated costs and may respond irrationally (although we provided some robustness checks). Fourth, this study only looked at informal sector workers in two (northern and western) out of four regions. Including the other regions would have given a more representative picture of the country.

Despite these limitations, the study constitutes a valuable contribution to the existing literature. It reveals that informal sector households are WTP more for a faith-based provider than a public provider and for an improvement in coverage. This sends out a clear message to policy makers that in establishing a health insurance scheme, the focus should be shifted to faith-based providers and the type of coverage. It also shows that households in urban areas and richer households are in general WTP more than their rural and poorer counterparts, which may call for targeted interventions.

\section{Appendix}

Table 9. Willingness to pay estimates per individual.

\begin{tabular}{llll}
\hline Attributes & Main Sample & $\begin{array}{l}\text { Rural } \\
\text { Location }\end{array}$ & $\begin{array}{l}\text { Urban } \\
\text { Location }\end{array}$ \\
\hline Total WTP & 8885.7 & 7450.1 & 10869.6 \\
Coverage & 6392.92 & 5700.01 & 7313.51 \\
Public Provider & 629.55 & 333.66 & 1032.06 \\
Faith-Based Provider & 6616.0 & 4812.54 & 9013.37 \\
Waiting Time $^{15}$ & 92.90 & 71.89 & 121.72 \\
\hline
\end{tabular}

Table 10. Regression results by income groups.

\begin{tabular}{|c|c|c|c|c|}
\hline \multirow{2}{*}{ Attributes } & Income One & Income Two & $\begin{array}{l}\text { Income } \\
\text { Three }\end{array}$ & $\begin{array}{l}\text { Income } \\
\text { Four }\end{array}$ \\
\hline & $\begin{array}{l}\text { Coefficient } \\
\text { (SE) }\end{array}$ & $\begin{array}{l}\text { Coefficient } \\
\text { (SE) }\end{array}$ & $\begin{array}{l}\text { Coefficient } \\
\text { (SE) }\end{array}$ & $\begin{array}{l}\text { Coefficient } \\
\text { (SE) }\end{array}$ \\
\hline Coverage & $\begin{array}{l}0.46218 \\
(0.02591)^{* * *}\end{array}$ & $\begin{array}{l}0.61116 \\
(0.02482)^{* * *}\end{array}$ & $\begin{array}{l}0.59434 \\
(0.04223)^{* * *}\end{array}$ & $\begin{array}{l}0.49872 \\
(0.06602)^{* * *}\end{array}$ \\
\hline Waiting & -0.00698 & -0.0087 & -0.00939 & -0.00121 \\
\hline Time & $(0.00113)^{* * *}$ & $(0.00108)^{* * *}$ & $(0.00184)^{* * *}$ & $(0.00285)$ \\
\hline Faith-Based & 0.83411 & 1.42279 & 1.16605 & 0.95991 \\
\hline Provider & $(0.05195)^{* * *}$ & $(0.05064)^{* * *}$ & $(0.08561)^{* * *}$ & $(0.06438)^{* * *}$ \\
\hline Public & -0.07766 & 0.22502 & 0.27598 & 0.27001 \\
\hline Provider & $(0.0511)$ & $(0.04815)^{* * *}$ & $(0.08268)^{* * *}$ & $(0.06494)^{* * *}$ \\
\hline Cost & $\begin{array}{l}-0.00008 \\
(8.53 \mathrm{e}- \\
06)^{* * *}\end{array}$ & $\begin{array}{l}-0.00009 \\
(8.10 \mathrm{e}- \\
06)^{* * *}\end{array}$ & $\begin{array}{l}-0.00009 \\
(0.00001)^{* * *}\end{array}$ & $\begin{array}{l}-0.00007 \\
(0.00002)^{* * *}\end{array}$ \\
\hline Constant & $\begin{array}{l}0.30080 \\
(0.09937)^{* * *}\end{array}$ & $\begin{array}{l}0.21344 \\
(0.12255)^{*}\end{array}$ & $\begin{array}{l}0.2046 \\
(0.06385)^{* * *}\end{array}$ & $\begin{array}{l}0.35392 \\
(0.10387)^{* * *}\end{array}$ \\
\hline $\begin{array}{l}\text { Mean } \\
\text { Income } \\
(\mathrm{SLL})\end{array}$ & 171284.40 & 298500 & 415633 & 556185 \\
\hline $\begin{array}{l}\text { No of } \\
\text { Observations }\end{array}$ & 3924 & 11736 & 9054 & 2412 \\
\hline Wald chi2 & 399.89 & 1411.34 & 693.81 & 158.02 \\
\hline Prob.>chi2 & 0.0000 & 0.0000 & 0.0000 & 0.0000 \\
\hline $\begin{array}{l}\text { Log } \\
\text { Likelihood }\end{array}$ & -2485.34 & -7283.33 & -5888.78 & -1584.32 \\
\hline
\end{tabular}

$* * * \mathrm{p}<0.01 ; * * \mathrm{p}<0.05 ; * \mathrm{p}<0.1$

${ }^{1}$ Moderate coverage is used to define coverage.

\section{References}

[1] Arhin-Tenkorang, D. (2001): Health Insurance for the Informal Sector in Africa: Design Features, Risk Protection, and Resource Mobilization. Health, Nutrition and Population Discussion Paper, World Bank.

15 Whilst these ratios will result in negative WTP, representing what individuals would need to be compensated for an increase in waiting time, the figures represented show WTP for a reduction in waiting time. 
[2] Asfaw, Gustafsson-Wright and van der Gaag (2009) WTP for health insurance: An analysis of the potential products for new lost cost health insurance in Namibia. Social Science and Medicine 69 (9): $135-159$.

[3] Bateman, I., R. Carson, B. Day, M. Hanemann, N. Hanley, S. Mourato, E. Ozdemiroglu, D. W. Pearce, and R. Sugden (2002): Economic Valuation with Stated Preference Techniques: a Manual. Cheltenham: Edward Elgar.

[4] Campbell, D (2006) Combining Mixed Logit Models and Random Effect Models to identify the determinants of willingness to pay for rural landscape improvements; Paper written for the Agricultural Economics Society $81^{\text {st }}$ Annual Conference, Reading, March 2006.

[5] Chaugule, S., Hay, J. W., and G. Young (2015): Understanding Patient Preferences and Willingness to Pay for Hemophilia Therapies. Patient Preference and Adherence 2015: 9; 1623 - 1630.

[6] Deaton, A., and C. H. Paxson (1997): The effects of economic and population growth on national saving and inequality. Demography 34 (1): $97-114$.

[7] De Bekker - Grob, E. W., Donkers, B., Jonker, M. F., E. A Stock (2015): Sample size requirements for Discrete Choice Experiments in Health Care: A Practical Guide. Patient (2015) 8: $373-384$.

[8] Donfouet, H. P, E. Makaudze, P. A. Mahieu, and E. Malin (2011) The determinants of willingness to pay for communitybased prepayment scheme in rural Cameroon. International Journal of Health Care Finance and Economics 11(3): $209-$ 220.

[9] Dong H, B. Kouyate, J. Cairns, F. Mugisha, and R. Sauerborn (2003) Willingness to pay for community based health insurance in Burkina Faso; Health Economics 12: 849 - 862.

[10] Escobar, M., C. C. Griffin, \& R. P. Shaw, (2010): The impact of Health Insurance in Low - and Middle - Income Countries. The Brookings Institution Press, Washington DC.

[11] Geidl, W., Knocke, K., Schupp, W., and K. Pfeifer (2018): Measuring Stroke Patient's Exercise Preferences using a Discrete Choice Experiment. Neurology International 2018; 10: 6993 .

[12] Ghosh, S., and S. Mondal, (2011): Morbidity, Health Expenditure and WTP for HI amongst the Urban Poor: A Case Study. Journal of Health Management 2011 13: 419.

[13] Greene, W. H., (2003) Econometric Analysis. Upper Saddle River: Prentice - Hall.

[14] Hanley, N., Mourato, S., and Wright, S. E (2001) Choice Modelling Approaches: A Superior Alternative for Environmental Valuation. Journal of Economic Surveys 15(3): $435-462$.

[15] Hanson, K.; and J. William (2010) Incentives that could induce Ethiopian doctors and nurses to work in rural settings; Health Affairs (Millwood) 29 (8): 1452 - 60 (Technical Appendix).

[16] Harapan, H., Fajar, J. K., Sasmono, R. T., and Kuch, U (2017): Dengue Vaccine Acceptance and Willingness to Pay. Human Vaccines and Immunotherapeutic 2017, Vol. 13 No. 4, 786- 790.

[17] Hensher, D. A.; J. M. Rose, and W. H. Greene, (2005): Applied Choice Analysis - A Primer. Cambridge University
Press, UK.

[18] Johnson, F. R.; E. Lancsar, E. Marshall, V. Kilambi, A. Muhlbacher, D. A. Regier, B. W. Bresnahan, B. Kanninen, J. F. P. Bridges, (2013): Constructing Experimental Designs for Discrete-Choice Experiments: Report of the ISPOR Conjoint Analysis Experimental Design Good Research Practices Task Force. Value in Health 16; 3-13.

[19] Justino, P. (2007): Social security in developing countries: Myth or necessity? Evidence from India, Journal of International Development, Vol. 32, No. 2, pp. 273 - 288.

[20] Kamara, F. S (2008) Economic and Social crises in Sierra Leone: The role of small-scale entrepreneurs in petty trading as a strategy for survival, 1990 - 1996; Bloomington, Indiana, US.

[21] Kielhorn, A. And J. M. Schulenburg, (2000): The health economics handbook. 2nd ed., Adis International Limited, England.

[22] Lancaster, K. (1966): A new approach to consumer theory, Journal of Political Economy, Vol. 74, pp. 132-157.

[23] Lancsar, E. and J. Louviere, (2008): Conducting Discrete Choice Experiments to Inform Healthcare Decision Making: a User's Guide. Pharmacoeconomics, 26 (8), pp. 661-677.

[24] Mangham, L. J., K. Hanson, and B. McPake, (2008) How to do (or not to do): Designing a discrete choice experiment for application in a low - income country; Health Policy Plan 2009, 24:151- 158 .

[25] Manski, C (1977) the structure of random utility models. Theory and Decisions 8 (3) 229 - 254.

[26] McFadden, D. (1974) Conditional logit analysis of qualitative choice behaviour, In P. Zarembka (ed.) Frontiers in Econometrics, New York: Academic Press, 105-142.

[27] Moia M, L. G Mantovani, M. Carpenedo, L. Scalone, M. S. Monzini, G. Cesana, and P. M. Mannucci (2013) Patient preferences and willingness to pay for different options of anticoagulant therapy; Intern Emerg Med 8: 237 - 243.

[28] Mooney, G. (2003): Economics, Medicine and Health Care, 3rd ed., Prentice Hall, London, U. K.

[29] Mulhern, B., Bansback, N., Hole, A. R., and Tsuchiya, A (2017): Using Discrete Choice Experiments with duration to model EQ - 5D - 5L Health State Preferences: Testing Experimental Design Strategies. Medical Decision Making 2017; 37: $285-297$

[30] Rakotonarivo, S., Schaafsma, M., and Hockley, N (2016): A Systematic Review of the reliability and validity of Discrete Choice Experiments in Valuing Non-Market Environmental Goods. Journal of Environmental Management 183 (Part 1) $98-109$.

[31] Ramsey, T. Z., Skov, M., Christensen, M. K., and Stahlhurt, C (2018): Frontal Brain Asymmetry and Willingness to Pay. Front. Neurosci. 12:138. 2018.

[32] Research for Development (2013) Closing the Gap: The global experience in providing health insurance coverage for informal sector workers.

[33] Ryan, M. and K. Gerard, (2003): 'Using discrete choice experiment to value health care programs: current practice and future research reflections'. Applied Health Economics and Health Policy, Vol. 2 (1), pp. 55-64. 
[34] Ryan, M.; Gerard, K., and Amaya - Amaya, M (2010): Using Discrete Choice Experiments to Value Health and Health Care (The Economics of Non-Market Goods and Resources). Springer, Dordrecht The Netherlands.

[35] Scott, A. (2001) Eliciting GP's preferences for pecuniary and non-pecuniary job characteristics; Journal of Health Economics, 20: $329-347$.

[36] Seghieri C, A. Mengoni, and S. Nuti (2014) Applying Discrete Choice Modeling in a Priority Setting: an Investigation of Public Preferences for Primary Care Models. European Journal of Health Economics 15: 773 - 785.

[37] Street, D. and L. B. Burgess (2007): The Construction of
Optimal Stated Choice Experiments: Theory and Methods, John Wiley and Sons, Hoboken, New Jersey.

[38] Terris - Prestholt, F., Quaife, M., and Vickerman, P (2016): Parameterising user uptake in Economic Evaluations: The Role of Discrete Choice Experiments. Health Economics 25 (Suppl. 1): $116-123$ (2016).

[39] Vroomen, J. M., and P. Zweifel (2011): Preferences for health insurance and health status: does it matter whether you are Dutch or German? European Journal of Health Economics (2011) 12:87-95.

[40] World Bank (2013)

http://data.worldbank.org/country/sierra_leone. 